\title{
Editorial
}

\section{The reform of psychiatric care in Greece: 1983-1989}

\author{
D Sarantidis ${ }^{1}$, V Kladouchos ${ }^{1}$, J Tripodianakis ${ }^{1}, \mathrm{R}$ Giel $^{2}$, P Munk-Jorgensen ${ }^{3}$ \\ 'Evangelismos General Hospital, Department of Psychiatry, Ipsilantou 45, Athens 106 76, Greece; \\ ${ }^{2}$ University of Groningen, Postbus 30.001, 9700 RB Groningen, The Netherlands; \\ ${ }^{3}$ Institute of Psychiatric Demography, Aarhus Psychiatric Hospital, Skovagervej 2, DK-8240 Risskov, Denmark
}

(Received 21 April 1992; accepted 24 August 1992)

\begin{abstract}
Summary - We have attempted to evaluate quantitative changes in the mental health delivery system in Greece, dictated by a fiveyear program to reform psychiatric care. By the end of the program, a number of psychiatric units in general hospitals, as well as community mental health centres, had been created, while the number of beds in psychiatric hospitals have been significantly reduced. Mental health services have become more accessible to the population, and served more patients. However, not all the objectives of the program have been met. Only about half of the initially proposed number of beds in the psychiatric units in general hospitals have been actually developed. The catchment area, a basic pre-requisite of the program, has not been put into effect. Finally, the noticeable trend towards a restriction of the role of psychiatric hospitals did not coincide with the development of adequate new services.
\end{abstract}

Mental Health Services / Greece

\section{Introduction}

For several reasons, discussed elsewhere (Sarantidis and Tripodianakis, 1989, 1990), Greece did not share the developments in psychiatric care that occurred in other European countries and in North America following the Second World War (Centre for Planning and Economic Research, 1976; Stephanis and Madianos, 1981; Madianos, 1983; Stephanis et al, 1986).

The need for modernization was more than obvious and became more urgent following Greece's accession to the European Economic Community (EEC) in 1981. In response to this need, an effort has been underway since 1984 to reform mental health services in Greece. The legal foundation for this effort was established by the Law 1397/83 (Government Gazette, 1983) "Re: the National Health System". The introductory section of this law states that "It is a common belief that psychiatric care in our country remains at an unacceptably low level. The psychiatric patient is frequently treated in such a way as to deprive him/her of his/her human dignity, even in its most elementary form." Article 21 of the Law 1397/83 provides for the creation of community mental health centres (CMHCs), psychiatric departments, in general hospitals, and a liaison between the various units which offer mental health services. This was followed by directive 815/84 (EEC Gazette, 1984) of the Commission of the European Communities (CEC), which anticipated funding $55 \%$ of the total cost of a five-year program to reform mental health services in Greece. The Commission also set up a committee of experts in order to study the conditions of psychiatric care in Greece and to draft and submit proposals to enable Greek authorities to initiate a program to reform psychiatric care in the Country (General Directorate for Employment, Social Affairs and Education of the CEC, 1983). Indeed, the Ministry of Health published in 1984 a five-year program containing some guidelines and objectives. The program aimed at the deinstitutionalization and the establishment of psychiatric units in general hospitals, and the creation of CMHCs and rehabilitation units.

Our aim was to evaluate public mental health services in Greece, by providing:

i) a description of the situation that existed in Greece, with regard to public psychiatric care, in 1983 , that is, just before the reform program began; ii) a description of the situation that existed in 1989 and a comparison with that of 1983 and 1987. 
Table I. Psychiatric units, available beds and ratio of beds/1000 inhabitants for each health district (HD) year 1983.

\begin{tabular}{|c|c|c|c|c|c|c|}
\hline \multirow[b]{2}{*}{$H D$} & \multicolumn{2}{|c|}{ Mental hospitals } & \multicolumn{2}{|c|}{ General hospitals } & \multirow{2}{*}{$\begin{array}{c}C M H C S \\
N\end{array}$} & \multirow{2}{*}{$\begin{array}{c}\text { Beds } \\
\text { per } 1000 \\
\text { inhabitants }\end{array}$} \\
\hline & $N$ & Beds & $N$ & Beds & & \\
\hline 1 & 3 & 3647 & 0 & 0 & 5 & 0.93 \\
\hline 2 & 1 & 400 & 0 & 0 & 0 & 0.31 \\
\hline 3 & 1 & 500 & 1 & 20 & 0 & 1.16 \\
\hline 4 & 0 & 0 & 0 & 0 & 0 & 0.00 \\
\hline 5 & 2 & 1463 & 0 & 0 & 2 & 0.86 \\
\hline 6 & 0 & 0 & 0 & 0 & 0 & 0.00 \\
\hline 7 & 0 & 0 & 1 & 16 & 0 & 0.05 \\
\hline 8 & 1 & 1648 & 0 & 0 & 0 & 3.85 \\
\hline 9 & 1 & 420 & 0 & 0 & 0 & 0.84 \\
\hline Total & 9 & 8078 & 2 & 36 & 7 & 0.83 \\
\hline
\end{tabular}

The private sector was not included in the paper, because the five-year program referred to the public sector only. In fact, the activity of the private sector was reduced, as a result of the implementation of Law 1397/83, which prohibited both the expansion of already established, and the development of new, private hospitals.

\section{Methodology}

Data were collected through direct correspondence with all Greek psychiatric units in three different periods, early in 1986 for the 1983 data and during 1988 and 1990, respectively, for the 1987 and 1989 data.

For the 1983 data we spoke to all the representatives of the mental health units existing at that time. More specifically, we asked all the psychiatric hospitals, the two general hospitals with psychiatric units, all the CMHCs, and the Mental Hygiene Centre, to provide data regarding the turnover of patients and the number of professional staff. The Mental Hygiene Centre is a nonprofit, State-controlled organization, which operates a number of CMHCs.

For the 1987 data, we adopted the same methodology, but included all the regional and prefectural general hospitals nationwide, since during that time the development of general hospital psychiatric units was in progress. In addition, we asked all the psychiatric hospitals, the general hospitals and the Mental Hygiene Centre whether they had developed any new CMHC. Finally, we asked the general hospitals whether they offered any psychiatric care in their health centres (HC). HCs were anticipated by Law $1397 / 83$. They were built and staffed after 1984 , mostly in the countryside. They are administered by the prefectural and regional general hospitals and provide primary care. The permanent medical staff consists of general practitioners, complemented by periodic visits (usually once a week) of specialists, including psychiatrists.

In the case of an affirmative answer, we requested statistics on patients and staff.

For the 1989 data, we added questions about the development of day hospitals, half-way houses, residential facilities and rehabilitation units.

Regarding the population figures in tables I and II, we used the statistics from the 1981 census. Finally, in presenting the situation in the psychiatric field, we used the division of the country into nine health districts (HDs). This division, effected by virtue of the Presidential Degree 31/1986, took place in 1986 and was solely administrative in nature. That is, it did not include the notion of a catchment area.

\section{The situation in 1983}

As can be seen in table I, in 1983, there was a strong disparity in the distribution of beds and other services among the various HDs. The most significant differences were:

i) the entire service delivery system was based on psychiatric hospitals. There was a total of nine psychiatric hospitals, as compared with just two psychiatric units in general hospitals; ii) the fourth (Thessally) and sixth (Eastern Macedonia) district had neither inpatient units nor CMHCs; iii) the 1st and 5th HDs, which include the large urban centres of Athens and Thessaloniki, did not have psychiatric units in general hospitals; iv) these two HDs were the only ones which offered CMHCs; v) the high ratio of beds $/ 1000$ inhabitants in the 8 th HD was due to the large psychiatric hospital on the is- 
Table II. Personnel and ratio of psychiatrists/100000 inhabitants for each health district (HD). Year 1983.

\begin{tabular}{cccc}
\hline & Psychiatrists & $\begin{array}{c}\text { Non-medical } \\
\text { personnel }\end{array}$ & $\begin{array}{c}\text { Psychiatrists } \\
\text { per } \\
\text { inhabitants }\end{array}$ \\
\hline 1 & & 100000 \\
2 & 92 & 14 & 2.35 \\
3 & 3 & 7 & 0.23 \\
4 & 8 & 0 & 1.80 \\
5 & 0 & 106 & 0.00 \\
6 & 37 & 0 & 2.18 \\
7 & 0 & 10 & 0.00 \\
9 & 2 & 4 & 0.58 \\
Total & 2 & 378 & 0.46 \\
\end{tabular}

land of Leros, which was mainly built for the relief of other psychiatric hospitals.

Table II contains personnel-related data. The highly unequal distribution of psychiatric staff, which was concentrated in HDs 1 and 5, is obvious.

\section{The situation in 1989}

The map in figure 1 gives an overall picture of the mental health units that were in operation at the end of 1989. It is obvious that the disparity that existed in 1983 has decreased. More specifically, the data gathered for 1987 and 1989 indicate the following.

\section{Creation of new units}

Between 1983 and 1989 (table III), the number of psychiatric hospitals remained unchanged. On the contrary, there was an impressive increase in the number of all the other units. The total number of general hospital psychiatric units increased from 2 to 33 (13 also offering inpatient psychiatric treatment).

Health centres did not exist in 1983. By the end of 1989, the number of HCs offering psychiatric treatment had risen from 0 to 51 . The total number of HCs in 1989 was 160 . Finally, the CMHCs increased from 7 to 17 .

\section{Available psychiatric beds}

As expected, the number of psychiatric beds in general hospitals increased from 36 to 233 (fig 2). However, there was an overall decrease of $14 \%$ in the number of available psychiatric beds. This was due to the reduction of beds in psychiatric hospitals (from 8078 in 1983 to 6731 in 1989).

\section{Patient turnover}

The total number of inpatient admissions increased by $32 \%$ (fig 3). Between 1983 and 1987, the psychiatric hospitals first showed an increase of $22 \%$ and then a decrease of $14 \%$. On the contrary, psychiatric units in general hospitals increased their admissions from 449 in 1983 to 1109 in 1987, and to 2616 in 1989. It appeared that general hospitals shared some of the patients' load with the psychiatric hospitals. As for the overall increase, it was probably at the expense of the private clinics, since the beds in psychiatric private hospitals were reduced from 5015 in 1983 to 4149 in 1989. However, it may also have been due to the application of less strict admission criteria by the psychiatric units of the general hospitals.

The total number of outpatient interviews increased from 41958 in 1983 to 144227 in 1989 (fig 4). This includes interviews in health centres as well as in general hospitals. The same figure shows that psychiatric hospitals exhibited a peak in 1987 that dropped in 1989.

\section{Mental health professionals}

The number of medical personnel (table IV) showed a steady increase from 1983 to 1989 . The number of registered nurses showed an initial decrease from 1983 to 1987 , probably due to a general shortage of registered nurses. However, in 1989 there was an increase, which can be attributed to the implementation of inpatient psychiatric units in general hospitals, as well as to the introduction of the specialty of psychiatric nursing. This has been in effect since 1985 and an increasing number 


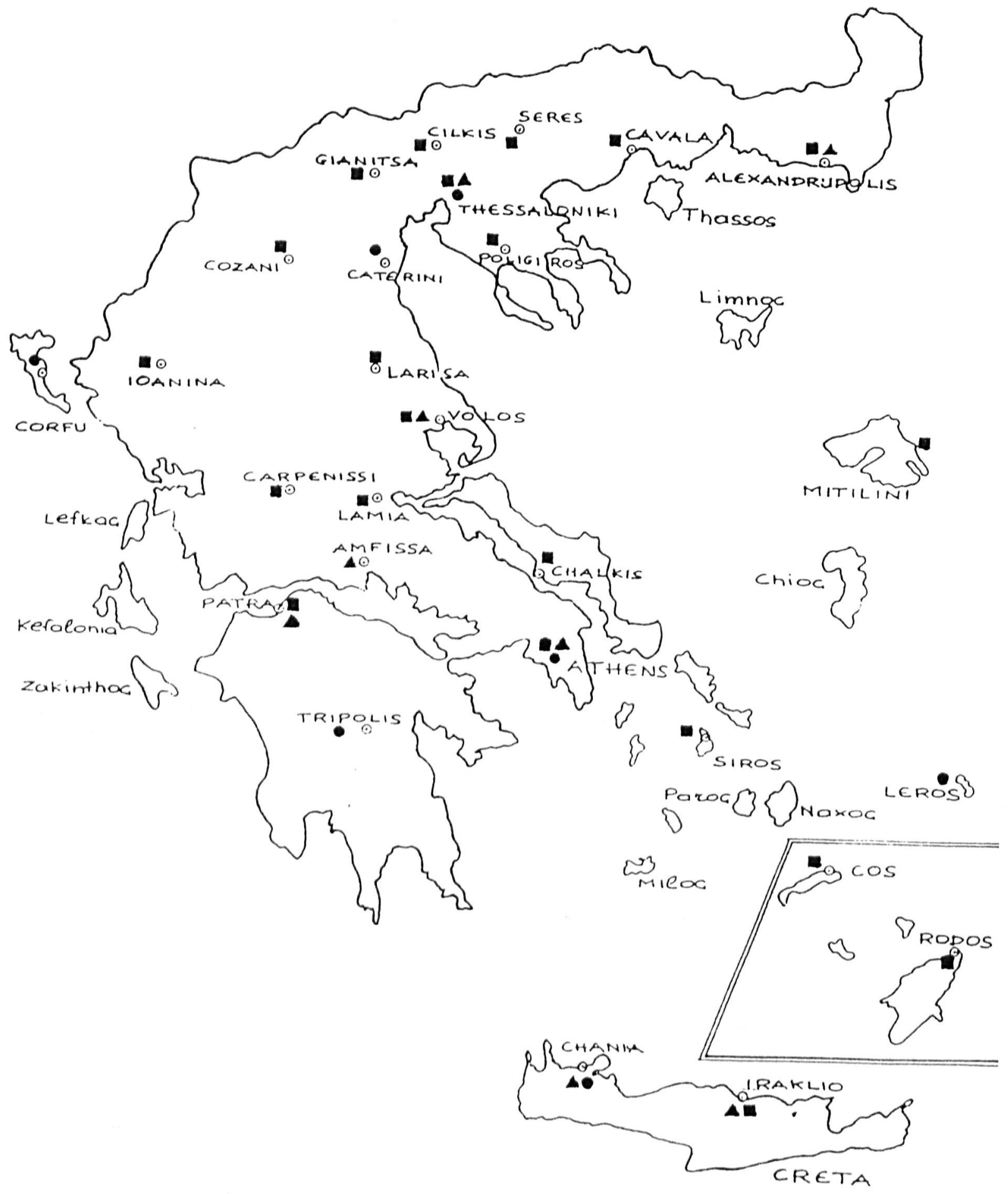

Fig 1. Mental health units in 1989.

psychiatric depts; $\triangle \mathrm{CMHC}$;

psychiatric hospitals. 
Table III. Units in operation (1983-1989).

\begin{tabular}{lccc}
\hline & 1983 & 1987 & 1989 \\
\hline Psychiatric hospitals & 9 & 9 & 9 \\
General hospitals with & 2 & 6 & 13 \\
inpatient psychiatric unit & & & \\
General hospitals, total & 2 & 29 & 33 \\
Health centres & 0 & 25 & 51 \\
CMHCs & 7 & 15 & 17 \\
\hline
\end{tabular}

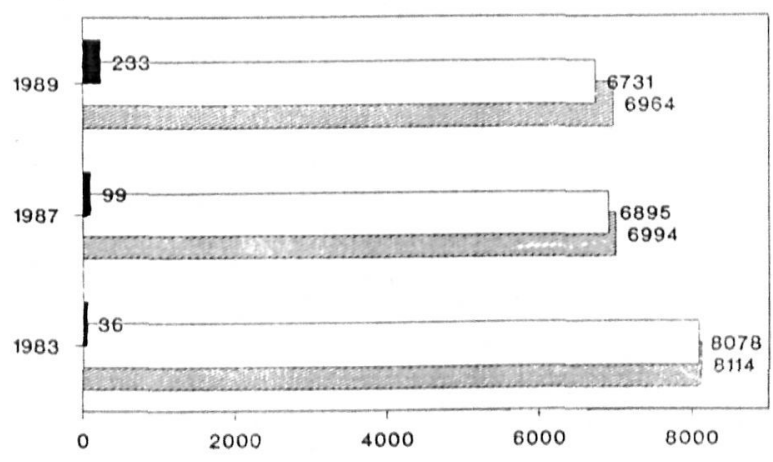

Fig 2. Number of beds. tals; $\mathbb{Z}$ total.

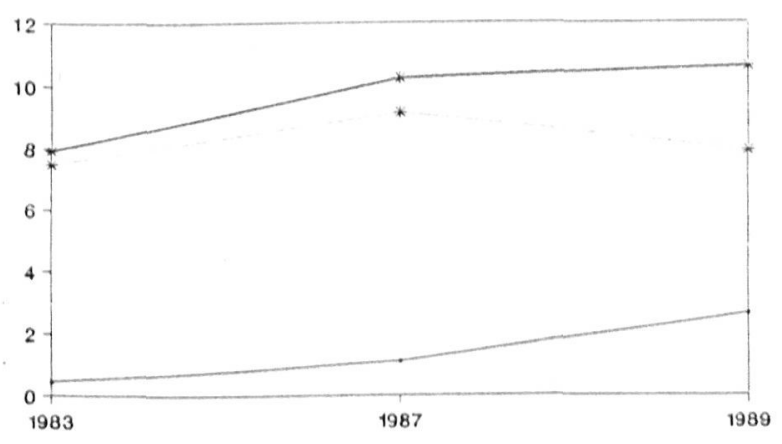

Fig 3. Number of admissions (in thousands). tals; --*-- mental hospitals; - *- total.

of nurses are choosing mental health as their specialty.

\section{Other units}

The availability of other units in 1989 is shown in table V. Data on these units were not collected for 1983 and 1987.

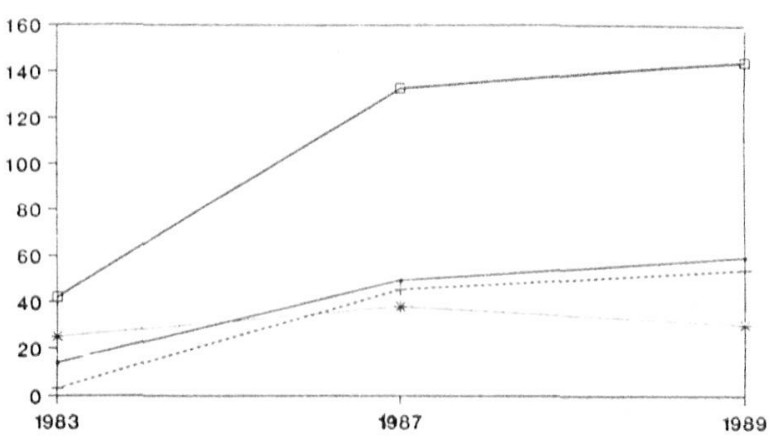

Fig 4. Outpatients interviews (in thousands). - $\mathrm{CMHC}$; ---- general hospitals; --*-- mental hospitals; $\square$ total.

Table IV. Number and profession of personnel (1983-1989).

\begin{tabular}{lrrr}
\hline & 1983 & 1987 & 1989 \\
\hline Psychiatrists & 148 & 300 & 363 \\
Residents & 124 & 207 & 276 \\
Psychologists & 16 & 68 & 111 \\
Social workers & 34 & 103 & 155 \\
Registered nurses & 320 & 255 & 505 \\
\hline
\end{tabular}

Table V. Patients' turnover in other units (1989).

\begin{tabular}{lcc}
\hline & Places & Served Patients \\
\hline Day hospitals & 225 & 225 \\
Halfway houses & 180 & 188 \\
Residential units & 125 & 138 \\
$\begin{array}{l}\text { Occupational } \\
\text { rehabilitation units }\end{array}$ & 315 & 338 \\
\hline
\end{tabular}

\section{Discussion}

Looking at the data, it can be said that up to 1983 , psychiatric care in Greece was characterized by:

i) an uneven distribution of psychiatric beds and psychiatrists over the various regions of the country; ii) a custodial structure with large, remote psychiatric hospitals and, with the exception of Athens and Thessaloniki, a total lack of extramural units; iii) the existence of only two psychiatric units in general hospitals located outside large cities; iv) a limited number of non-medical mental health professionals. 
Stephanis and Madianos (1981), referring to the state of psychiatric care in Greece in 1978, described it as centralized, with an uneven distribution of psychiatrists and other staff among the various psychiatric hospitals and an uneven distribution of funds. The Centre for Planning and Economic Research of Greece (1976) reported that psychiatric care in Greece was characterized by geographically uneven distribution, insufficient development of extramural units, incomplete integration of psychiatric services within the general health system, outdated hospitals, social inequality, qualitative inadequacy due to the custodial structure and insufficient staff and funding. Two subsequent studies drew similar conclusions (Madianos, 1983; Stephanis et al, 1986).

Looking at the 1989 data, it seems that definite progress has been made. The volume of mental health services has increased and the uneven distribution has diminished. Psychiatric services have been more accessible to the population in the countryside and on the islands through psychiatric coverage of health centres. Patients are being diverted from psychiatric hospitals to the psychiatric units in general hospitals. Finally, a development of aftercare facilities such as halfway houses and residential facilities has already started.

However, taking the Ministry of Health's (1984) five-year program as the official guideline, we note the following divergences from its objectives.

For the five-year period 1984-1988, $20 \mathrm{CMHCs}$ were anticipated. At the end of 1989 there were 17. Two more centres were opened in 1990. Thus, two years later, the objective regarding $\mathrm{CMHCs}$ had still not been met. Twenty-eight psychiatric units were foreseen in general hospitals, and in 1989, 33 were operating. However, of these, only $39 \%$ of fered inpatient care. Thus, the objective of 598 beds by the end of 1988, which was anticipated in the report, has not been met, since, one year after the end of the five-year program, only 233 beds were available. Finally, the reduction in the number of psychiatric hospital beds had almost been achieved by the end of 1989. The goal of the program had been to reduce the number of beds to 6660 by the end of the plan.

Thus, despite the improvement in the number of available units and the population served, it appears that there has been a problem in coordinating the development of the services. This indicates that the organizational infrastructure was not effective. For example:

Despite a temporal increase in 1987, the psychiatric hospitals provided in 1989 approximately the same volume of services (both admissions and
Table VI. Personnel of psychiatric hospitals.

\begin{tabular}{lrr}
\hline & 1983 & 1989 \\
\hline Psychiatrists & 126 & 189 \\
Residents & 111 & 171 \\
Psychologists & 9 & 36 \\
Registered nurses & 315 & 392 \\
Social workers & 26 & 51 \\
\hline
\end{tabular}

outpatient care) as in 1983 (admissions were 7495 in 1983 and 7906 in 1989 - outpatient interviews were 24983 in 1983 and 30483 in 1989). However, personnel increased considerably (table VI). This increased manpower and an almost constant number of admissions should have led to an increased number, at least, of outpatient interviews.

The unmet objectives of development of general hospital psychiatric units and CMHCs, emphasizes the difficulty of creating community based services, which require greater mobilization of resources. On the contrary, the objective of reducing the beds in psychiatric hospitals was met rather easily. This has been the case in other countries as well (eg Okin, 1978; Braun et al, 1981; Scull, 1985; Rizzardo et al, 1986; Thornicroft and Bebbington, 1989).

The catchment area, a basic prerequisite according to both the CEC committee of experts and the Ministry of Health, was not put into effect, nor is there any visible movement to do so, despite the fact that many proposals have been made to establish such areas.

Concerning training and education of personnel, despite some improvement, problems still exist. The separation of Neurology from Psychiatry was implemented in 1981 and the trainees now spend three years in Psychiatry and one year in Neurology. However, a large proportion continues to spend all three years in psychiatric hospitals, which means that they do not acquire experience in other units.

Perhaps the most obvious problem is the lack of mechanisms to evaluate the care offered. Evaluation of the whole program has just started, whereas evaluation of individual programs are, for the time being, out of the question, as is any reference to quality assurance programs.

\section{Conclusion}

Greece tried to reform the mental health services over a relatively short period of time. The plan was very ambitious, if one takes into account the finan- 
cial and managerial resources of the Greek state. Despite the marked improvement in the care offered, there are still problems in the administration and evaluation of this care.

\section{References}

Braun P, Kochansky G, Shapiro R, Greenberg S, Guteman EJ, Johnson S, Shore FM (1981) Overview: deinstitutionalization of psychiatric patients, a critical review of outcome studies. Am J Psychiatry 136, 736-749

Centre for Planning and Economic Research (1976) Report of a Working Group. Developmental Program 1976-1980. Health. No 12, Mental Health. Athens (in Greek)

EEC Gazette, L88/31, EEC Directive No 815/84. March 1984.

General Directorate for Employment, Social Affairs and Education (Dec 1983) Report of the Study Group on Psychiatric Care in Greece. Commission of the European Communities

Government Gazette 143/7 Oct (1983) Law 1397. "Re: the National Health System" (in Greek)

Madianos M (1983) Mental illness and mental health care in Greece. Public Health Rev 11, 79-93

Ministry of Health and Social Affairs (1984) Five Year
Mental Health Program and First Phase Program within the Framework of the Special EEC Funding Support (Dir 815/84) (in Greek)

Okin LR (1978) The future of State mental health programs for the chronic psychiatric patient in the community. Am J Psychiatry 135, 1355-1358

Rizzardo R, Rovea A, Magni G (1986) The general practitioner and the psychiatric health service in Italy after the reform: opinions and experiences in an urban district. Acta Psychiatr Scand 73, 234-238

Sarantidis D, Tripodianakis J (1989) The five year program to reform psychiatric care in Greece. Tetradia Psychiatrikis 27, 14-21 (in Greek)

Sarantidis D, Tripodianakis J (1990) Characteristics of psychiatric care in Greece in the year 1983. Psychiatriki 1, 209-215 (in Greek)

Scull A (1985) Deinstitutionalization and public policy. Soc Sci Med 20, 545-552

Stephanis NC, Madianos GM (1981) Mental health care delivery system in Greece. A critical overview. In: Aspects of Preventive Psychiatry (Christodoulou GN, ed). Karger, Basel

Stephanis NC, Madianos GM, Gittelman M (1986) Recent developments in the care, treatment and rehabilitation of the chronic mentally ill in Greece. Hosp Community Psychiatry 37, 1041-1044

Thornicroft G, Bebbington P (1989) Deinstitutionalization - from hospital closure to service development. Br J Psychiatry 155, 739-753 